\title{
Pork Jerky Fermented with Lactobacillus bulgaricus and Angel Yeast
}

\author{
Changqing Zhao*, Zhuochi Chen and Yubin Li \\ College of Bioengineering, Sichuan University of Science and Engineering, Zigong \\ 643000, China
}

\section{A B S T R A C T}

Lactobacillus bulgaricus and Angel Yeast was used to produce fermented pork jerky, and a series of indexes were measured. The results demonstrated that the $\mathrm{pH}$ of the fermented jerky was lower than the non-fermented jerky; the true protein content of the fermented jerky was lower than that of the nonfermented jerky; the free amino acids content of the fermented jerky was higher than the non-fermented jerky; the acid protease activity was slightly higher than the neutral protease activity in the fermented jerky; four and fifteen volatile compounds were detected for the non-fermented and fermented jerky, respectively. The important compounds affecting the flavor of fermented jerky included DL-Glutamic Acid, Phenylethyl Alcohol, 1-Octen-3-ol, Nonanal, Pentanal, 3-Methyl-Butanal, and 2-Pentyl-Furan. The study results demonstrated that the strains combined with Lactobacillus bulgaricus and Angel Yeast reduced the meat $\mathrm{pH}$, degraded the protein in the meat by the proteases (including acid and neutral proteases) produced during fermentation, and increased the amount of free amino acids and flavored compounds. In these ways, the meat texture and taste were improved, and digestion and absorption were enhanced.
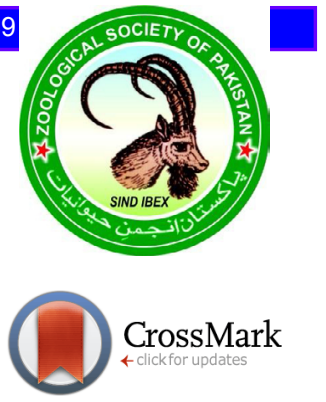

\section{INTRODUCTION}

$\mathrm{P}$ ork jerky is a popular Chinese food. However, in the traditional production process, the meat jerky is dehydrated, which results in hard texture and poor color (Konieczny et al., 2007). However, after the fermentation process, not only is the meat tenderized with improved texture, but the acids, alcohols, and non-protein nitrogen compounds produced during fermentation give the meat a unique flavor and enhance the nutritional value. At the same time, the fermentation causes the specific bacteria, yeasts, or molds to reduce the meat $\mathrm{pH}$, and the low temperature dehydration can reduce the water activity $\left(\mathrm{A}_{\mathrm{w}}\right)$ as well, inhibiting food pathogens (such as Listeria and Staphylococcus aureus (Aqib et al., 2017)) and increasing food safety (Li and Lv, 2005). Thus, fermented pork jerky is beneficial in a variety of ways.

In recent years, there have been some reports about using single strains to ferment meat which mainly include Lactobacillus (Lee et al., 2006), Micrococci (Drosinos, 2006), Staphylococcus (Visessanguan et al., 2006), yeasts (Hammes and Knauf, 2001) and moulds (Li et al., 2004; Wang, 2013). However, no other published reports were found on pork jerky produced with fermentation. In our previous experiments, single

\footnotetext{
* Corresponding author: zhaocq2010@163.com 0030-9923/2018/0005-1763 \$ 9.00/0

Copyright 2018 Zoological Society of Pakistan
}

Lactobacillus bulgaricus and single Angel Yeast were used to ferment pork meat and it was found that both of them had ability to improve the texture, the color and the flavor of pork. However, there are some flaws.

Lactobacillus bulgaricus alone results in an unpleasant, sour flavor, while pork jerky made through fermentation with Angel yeast alone contains too low free amino acids. In order to improve the flaws, the compound strains of the Lactobacillus bulgaricus and the Angel Yeast were selected for meat fermentation.

In this study, the pork was fermented with the Lactobacillus bulgaricus and the Angel Yeast, and some indexes were detected including $\mathrm{pH}$ value, free amino acids contents, protease activities of the fermented pork jerky, the non-fermented jerky, the remaining fermented medium, and the medium before fermentation.

\section{MATERIALS AND METHODS}

\section{Materials}

Biochemical-grade yeast extract, peptone and bovine serum albumin were purchased from Beijing AoBoXing Leiverseen Biotech Co. Ltd. (Beijing, China). All other reagents used were of research-grade quality.

\section{Media}

MRS solid medium

Peptone $10 \mathrm{~g}$, beef extract $10 \mathrm{~g}$, yeast extract $5 \mathrm{~g}$, diammonium citrate $2 \mathrm{~g}$, sodium acetate $5 \mathrm{~g}, \mathrm{~K}_{2} \mathrm{HPO}_{4} 2 \mathrm{~g}$, 
$\mathrm{MnSO}_{4} \cdot 4 \mathrm{H}_{2} \mathrm{O} 0.25 \mathrm{~g}, \mathrm{MgSO}_{4} \cdot 7 \mathrm{H}_{2} \mathrm{O} 0.58 \mathrm{~g}$, glucose $20 \mathrm{~g}$, tween $80 \mathrm{~mL}$, agar $25 \mathrm{~g}$, water $1,000 \mathrm{~mL}$. The $\mathrm{pH}$ was adjusted to 6.2-6.4 and the medium was autoclaved at $121^{\circ} \mathrm{C}$ for $15 \mathrm{~min}$.

\section{Lactobacillus medium}

Glucose $10 \mathrm{~g}$, lactose $5 \mathrm{~g}, \mathrm{NaCl} 5 \mathrm{~g}$, water $1,000 \mathrm{~mL}$. The $\mathrm{pH}$ was adjusted to $6.5-6.8$, and the medium was aliquoted and autoclaved at $121^{\circ} \mathrm{C}$ for $20 \mathrm{~min}$.

\section{PDA solid medium}

$200 \mathrm{~g}$ of peeled potatoes were diced and boiled in water for $30 \mathrm{~min}$. Then, they were filtered through four layers of gauze. The filtrate was mixed with $20 \mathrm{~g}$ of glucose, and then $20 \mathrm{~g}$ of agar. It was then supplemented with up to $1000 \mathrm{~mL}$ of water. After being heated, the filtrate was placed into a test tube and sterilized for $20 \mathrm{~min}$ at $121^{\circ} \mathrm{C}$.

\section{PDA liquid medium}

$200 \mathrm{~g}$ of peeled potatoes were diced and boiled in water for $30 \mathrm{~min}$. Then, they were filtered through four layers of gauze. The filtrate was mixed with $20 \mathrm{~g}$ of glucose. It was then supplemented with up to $1,000 \mathrm{~mL}$ of water, placed into a triangular flask, and sterilized for 20 $\min$ at $121^{\circ} \mathrm{C}$.

\section{Bacteria strains}

The Lactobacillus bulgaricus and Angel Yeast used in the experiment were preserved in our laboratory. Before use, the Lactobacillus bulgaricus was inoculated onto the MRS solid medium and cultured for $48 \mathrm{~h}$. The Angel yeast was inoculated onto the PDA solid medium and cultured for $48 \mathrm{~h}$.

\section{Preparation of fermented pork jerky}

1. The pre-treatment of raw pork: The inspected fine commercial pork was cut into $500 \mathrm{~g}$ pieces and soaked in cold water for about $1 \mathrm{~h}$ to remove residual blood. The pork pieces were then dried and weighted.

2. Precooking: The pork pieces were precooked with sodium chloride in water for $10 \mathrm{~min}$. They were frequently flipped to ensure uniform cooking.

3. Cutting: After precooking, the pork pieces were kept in a perforated plastic container. After cooling, the meat was cut into slices measuring $2.5 \mathrm{~cm} \times 1.5 \mathrm{~cm} \times 0.5$ $\mathrm{cm}$ with neat sheet-shaped and uniform thickness.

4. Fermentation: The Lactobacillus bulgaricus was inoculated onto the MRS solid medium, and the Angel yeast was inoculated onto the potato fluid medium. They were cultured continuously at 100RPM for $24 \mathrm{~h}$ at $30^{\circ} \mathrm{C}$ of constant temperature. Then, $25 \mathrm{~mL}$ of the Lactobacillus bulgaricus culture solution and Angel yeast culture solution were placed into a $100 \mathrm{~mL}$ flask that had been dried for two hours at $160{ }^{\circ} \mathrm{C}$ in a blast drying oven. This mixture was to be used as the fermentation broth (the initial concentrations of the Lactobacillus bulgaricus and the Angel yeast were $3.8 \times 10^{7} \mathrm{CFU} / \mathrm{mL}$ and $1.5 \times 10^{5} \mathrm{CFU} /$ $\mathrm{mL}$, respectively). The broth's $\mathrm{pH}$ value was adjusted to 6.5. Then, $25 \mathrm{~g}$ of pretreated sliced meat was placed into the flask, which was then sealed with plastic film, labeled, and put into a constant temperature incubator at $25^{\circ} \mathrm{C}$ for $42 \mathrm{~h}$. The fermentation medium (without meat) was cultured under the same condition as the control groups.

5. Cooking and baking: The fermented meat was transferred to spice-free boiling water to re-cook for 10 min, with frequent gentle stirring for uniform cooking. Then it was transferred to an oven and heated at $100{ }^{\circ} \mathrm{C}$ for $10 \mathrm{~min}, 80^{\circ} \mathrm{C}$ for $30 \mathrm{~min}$, and then $60^{\circ} \mathrm{C}$ for $90 \mathrm{~min}$. After cooling, the fermented pork jerky was ready. The nonfermented pork jerky was made through the same process excluding the fermentation step.

\section{Product indices determination \\ The determination of $\mathrm{pH}$}

A solid sample of $1 \mathrm{~g}$ was ground finely in a mortar

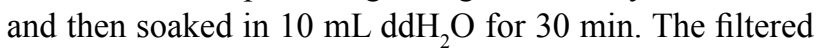
solution was used for measurement with a $\mathrm{pH}$ meter. The liquid sample was directly used for $\mathrm{pH}$ measurement. The solid samples included non-fermented and fermented pork jerky; and the liquid samples included the remaining fermented medium, and the medium before fermentation.

\section{Determination of true protein content}

Non-fermented and fermented pork jerky samples of $10 \mathrm{~g}$ were weighted respectively. Then 5 times of trichloroacetic acid (TCA) solution with $10 \%(\mathrm{w} / \mathrm{w})$ concentration were used to extract the true protein from the jerky (Zhou, 1996). After stirring and standing for 10 min, the samples were filtered. The residues were rinsed with 5 times of TCA solution twice and then dried in an oven at $105^{\circ} \mathrm{C}$. Finally, a $0.2 \mathrm{~g}$ solid sample was digested in a digestion tube and the nitrogen content was measured with an automatic Kjeldahl analyzer (HR-500, Shanghai Hua Rui Instrument Co., Ltd., China). The formula for true protein content was as follows:

$$
\mathrm{X}=\mathrm{W} \times \mathrm{F}
$$

Where, $\mathrm{X}$ is the protein content of the samples (\%), W is the nitrogen content measured by automatic Kjeldahl analyzer (\%) and $\mathrm{F}$ is the nitrogen-to-protein conversion factor ( 6.25 was used here). This led to the calculation of $\mathrm{W} \times$ to obtain the protein content. 


\section{Determination of total free amino acids}

The free amino acid contents of the samples, including non-fermented pork jerky, fermented pork jerky, remaining fermented medium, and the medium before fermentation, were determined using the colorimetric method of ninhydrin (Zhang, 2005). Accordingly, ninhydrin was added to the samples under acidic conditions and the absorbance of the solution was ascertained at $570 \mathrm{~nm}$.

\section{Determination of protease activity}

Folin-phenol reagent (Wu et al., 2006) was used to measure the neutral and acid protease activities in the samples including the fermented jerky, the remaining fermented medium with meat, the fermented medium without meat, and the medium before fermentation.

\section{Determination of flavor compounds \\ Extraction of volatile components by headspace solid phase microextraction (SPME)}

A headspace solid-phase microextraction (HSSPME) holder (Supelco Inc., Shanghai, China) for manual sampling, combined with gas chromatography-mass spectrometry (GC-MS) (Agilent Technologies, USA), was used to perform the experiments. Teflon covers and a $75-\mu \mathrm{m}$ carboxen/polydimethylsiloxane fiber were purchased from Supelco Inc. Before initial use, the fiber was preconditioned for $2 \mathrm{~h}$ on an Agilent 6890-5975 gas chromatograph at an injector temperature of $230^{\circ} \mathrm{C}$. Then, the minced samples of non-fermented pork jerky and fermented pork jerky ( $3 \mathrm{~g}$ ) were respectively placed in a $15-\mathrm{mL}$ vial at room temperature, and the vial was sealed with a Teflon cover, heated at $60^{\circ} \mathrm{C}$ in a water bath for $30 \mathrm{~min}$, and mixed at intervals. The HS-SPME fiber was inserted for sampling for $40 \mathrm{~min}$, which was adequate to extract the volatile compounds from the samples and introduce them into the GC-MS injector for desorption for $5 \mathrm{~min}$.

\section{GC-MS analysis}

The GC-MS analysis was performed on an Agilent 6890 gas chromatograph coupled with a 5975 mass spectrometer (Agilent Technologies, USA). The carrier gas was helium with a flow rate of $1.1 \mathrm{~mL} / \mathrm{min}$. The separation was performed on a DB-WAX $30 \mathrm{~m} \times 0.25 \mathrm{~mm}$ $\times 0.25 \mu \mathrm{m}$ capillary column (Agilent Technologies, USA). The initial oven temperature was $35^{\circ} \mathrm{C}$ for $1 \mathrm{~min}$, which was ramped to $100{ }^{\circ} \mathrm{C}$ at the rate of $8{ }^{\circ} \mathrm{C} / \mathrm{min}$ and held for $3 \mathrm{~min}$; subsequently, the temperature was ramped to $120^{\circ} \mathrm{C}$ at the rate of $3{ }^{\circ} \mathrm{C} / \mathrm{min}$ and held for $2 \mathrm{~min}$; finally, the temperature was ramped to $230{ }^{\circ} \mathrm{C}$ at the rate of $5^{\circ} \mathrm{C} /$ min and held for $5 \mathrm{~min}$. The mass detector was operated at $230{ }^{\circ} \mathrm{C}$ in an electron impact mode at $70 \mathrm{eV}$. The ion-source temperature was $230{ }^{\circ} \mathrm{C}$, while the transfer line temperature was $150{ }^{\circ} \mathrm{C}$. The chromatograms were recorded by monitoring the total ion currents in the 20 350 mass range.

\section{Data analysis}

The data obtained were analyzed using MSD Productivity ChemStation Data Analysis Software (version G1701DA). Identification of volatile compounds was confirmed by comparing their mass spectra with those in the National Institute for Standards and Technology (NIST, Search Version 2.0) and Pesticides Retention Time Lock (RTLPEST, Parts number G1672AA, version A.03.00) mass spectral library. Determination of the percentage composition was based on peak area normalization (expressing the area of a given peak as a percentage of the sum of the areas of all the peaks) without the use of correction factors.

\section{RESULTS AND DISCUSSION}

\section{pH change before and after fermentation}

As shown in Figure 1A, the $\mathrm{pH}$ of the fermented pork jerky (4.75) was significantly lower than that of the nonfermented jerky (6.42), and the $\mathrm{pH}$ of the medium after fermentation (4.71) was lower than before fermentation (6.50). This indicated that during fermentation, the Lactobacillus produced lactic acid and acidic acid, and reduced the $\mathrm{pH}$ of the fermented jerky and medium. The reduced $\mathrm{pH}$ inhibited the growth and reproduction of adverse microorganisms, especially spoilage bacteria, thus potentially extending the shelf life of jerky and improving preservation. At the same time, the lower $\mathrm{pH}$ promoted the reduction of nitrite and decreased the amount of residual nitrite, thereby reducing the carcinogens - nitrosamines produced by nitrite and secondary amines.

In addition, due to the participation of the yeast, the fermented pork jerky smelled of fermented glutinous rice, which improved flavor and taste as the yeast produced significant amounts of alcohols. Compared with our previous experiment that the $\mathrm{pH}$ value of the pork jerky fermented at the same condition through the single Lactobacillus bulgaricus was 4.13 (not shown in tables or figures), the $\mathrm{pH}$ value of the pork jerky fermented by the Lactobacillus bulgaricus and the Angel Yeast was higher (pH of 4.75) which were more acceptable for people. This was because that the Lactobacillus bulgaricus had strong ability to produce acid but the Angel Yeast had faintish ability to produce acid and thus the compound strains not only improved the flavor of the pork but also inhibit the ability of the Lactobacillus bulgaricus to produce acid. 


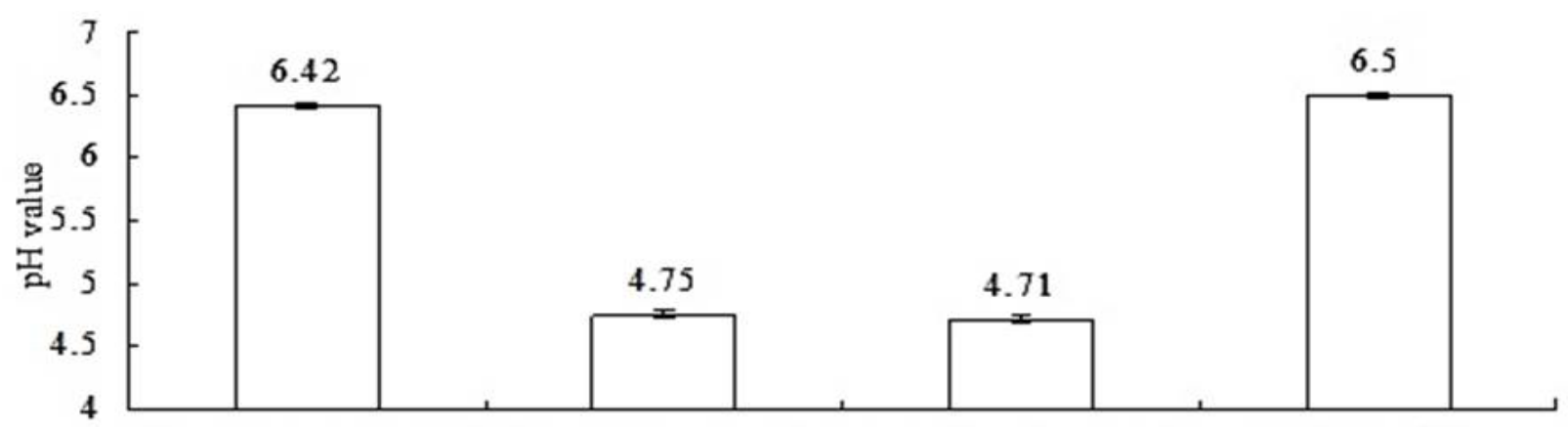

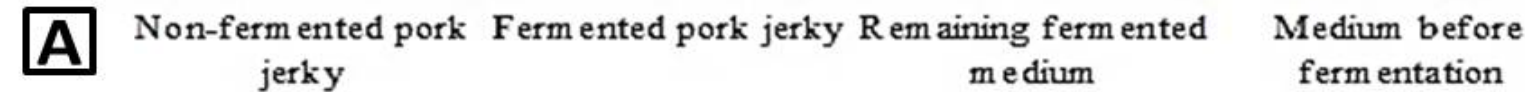
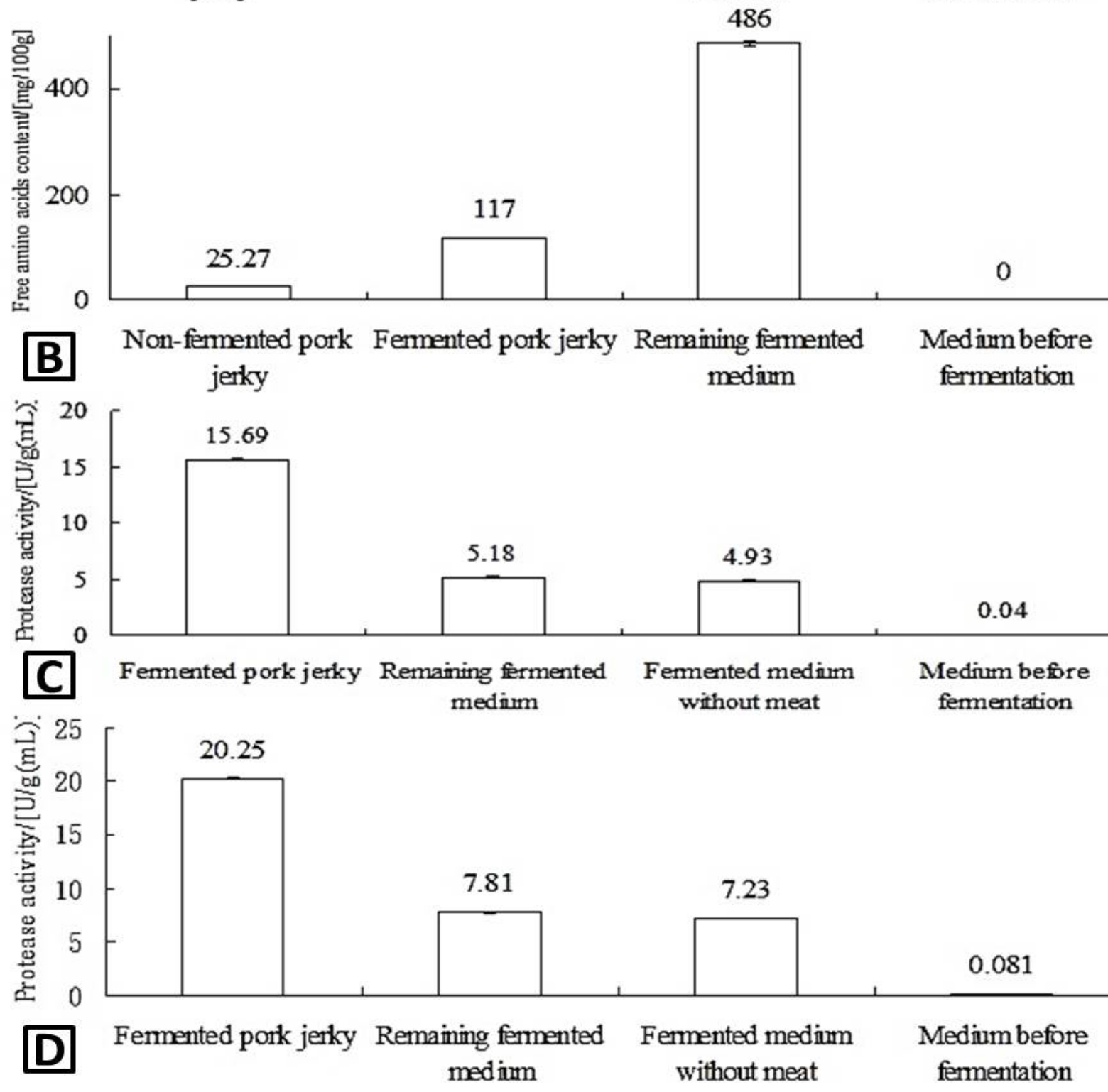

Fig. 1. pH change (A), free amino acids content (B), neutral protease activity (C) and acid protease activity (D) before and after fermentation. 
True protein content change before and after fermentation

The content of protein in fresh meat is about $20 \mathrm{~g} / 100 \mathrm{~g}$ ( $\mathrm{Gu}$ et al., 2009). In this experiment, as the non-fermented and the fermented pork jerky were baked samples which lost water in the baking process, the higher true protein contents were obtained for the non-fermented and fermented pork jerky samples of $81.09 \mathrm{~g} / 100 \mathrm{~g}$ and $68.50 \mathrm{~g} / 100 \mathrm{~g}$, respectively (Table I). From comparison, it could be seen that the fermented jerky has significantly less protein than the non-fermented jerky. This indicated that during the fermentation process, the Lactobacillus hydrolyzed a portion of the pork protein and produced higher proportions of polypeptides and abundant amino acids. Consequently, the fermented products became easier to digest and absorb, and offered better biochemical availability.

Table I.- True protein content of pork jerky before and after fermentation.

\begin{tabular}{lc}
\hline Sample & Protein content $(\mathbf{g} / \mathbf{1 0 0} \mathbf{g})$ \\
\hline Non-fermented pork jerky & 81.09 \\
Fermented pork jerky & 68.50 \\
\hline
\end{tabular}

\section{Total free amino acids before and after fermentation}

The content of free amino acids (which can be easily assimilated by humans) is an important parameter for the evaluation of the nutritional value of pork (Chen and Liu, 2004). The levels of free amino acids in the jerky and media before and after fermentation were shown in Figure 1B. As could be seen, there was a significant difference in the free amino acids content between the fermented and non-fermented jerkies. The amino acid content in the fermented jerky $(117.0 \mathrm{mg} / 100 \mathrm{~g})$ was 3.5 times that of the non-fermented jerky $(25.27 \mathrm{mg} / 100 \mathrm{~g})$. It was also discovered that the free amino acids content was higher in the medium after fermentation than before fermentation. Combined with the protein content change of the jerkies before and after fermentation, the results indicated that as the protein in the fermented jerky decreased, the free amino acids increased. This was because the protein was degraded and produced free amino acids, part of which remained in the jerky to improve the flavor, and part of which was left in the fermentation medium. Thus, the medium after fermentation had much a higher free amino acids content than before fermentation $(0 \mathrm{mg} / 100 \mathrm{~g})$. These free amino acids by themselves can enhance fermented meat flavor, and they can also serve as substrates for further production of flavor compounds, improving a product's flavor and taste.

In addition, the content of free amino acids in the pork jerky fermented with the compound strains (117.0 $\mathrm{mg} / 100 \mathrm{~g}$ ) was all more than the content of the raw pork $(64.0 \mathrm{mg} / 100 \mathrm{~g})$ and the content of the pork jerky fermented by the single Angel Yeast $(68.3 \mathrm{mg} / 100 \mathrm{~g})$ or the single Lactobacillus bulgaricus $(62.0 \mathrm{mg} / 100 \mathrm{~g})$ (results of previous experiments). It showed that the compound strains were with strong ability to produce free amino acids in the fermentation when fermentation with the Lactobacillus bulgaricus and the Angel Yeast.

\section{Protease activity changes before and after fermentation}

As shown in Figure 1C and D, the neutral and acid protease activities in the fermented jerky were much higher than in the medium both before and after fermentation. The protease activities were in the following order: fermented jerky $>$ remaining fermented medium $>$ fermented medium without meat $>$ medium before fermentation (inoculation medium). This was because most of the Lactobacillus were immobile. During fermentation, the media were kept still in the incubator without shaking. After mass consumption of the surrounding nutrition in the medium, the immobile Lactobacillus used substances inside and close to the meat, changed the nutrients and texture of the meat, and tenderized the meat. Meanwhile, the remote Lactobacillus would autolyse due to nutritional deficiencies and aging. Therefore, the fermented jerky had higher protease activities than the remaining fermented medium.

Furthermore, acidic protease activities in the fermented jerky $(20.25 \mathrm{U} / \mathrm{g})$, and the remaining fermented medium $(7.81 \mathrm{U} / \mathrm{mL})$ were both a little higher than the neutral protease activities $(15.69 \mathrm{U} / \mathrm{g}$ and $5.18 \mathrm{U} / \mathrm{mL}$, respectively). This was because the optimal fermentation condition for Lactobacillus bulgaricus and Angel Yeast was both acidic ( $\mathrm{pH}=6.5$ and 4.5 , respectively), which also meant that it was appropriate for Lactobacillus bulgaricus to produce fermented jerky under acidic conditions.

\section{Changes in flavor substances before and after fermentation}

Meat fermentation is accompanied by complex chemical changes, primarily including carbohydrate, protein, and fat degradation. Precursors in meat such as sugars, amino acids, sulfur-containing amino acids, lipids, thiamine, nucleotides, and peptides undergo a series of changes to generate volatile and nonvolatile components, which then interact to form final flavor substances (Zhang et al., 2013). Meat flavors refer to the fresh meat smell, and the aroma and taste of heated meat and meat products. They result from the various organic compounds generated from complex physiological and biochemical changes in components inherent in meat; meat aroma is primarily reflected by sulfur-containing compounds (Xia, 2008). Whether a compound can generate smell and taste depends on its odor threshold; the contribution of a volatile substance to the aroma and total meat flavor depends on 
the ratio of the substance's concentration to odor threshold (OVA). A substance can be detected and called a flavor substance only when its OVA is greater than 1 (Fan and $\mathrm{Xu}, 2014)$.

As shown in Table II, gas chromatography and mass spectrometry revealed that the non-fermented pork jerky contained four volatile flavor substances, while the fermented pork jerky contained fifteen volatile flavor substances, including two acids ( $0.67 \%$ total content), six alcohols (12.16\% total content), five aldehydes $(71.94 \%$ total content), two alkanes (2.01\% total content), and two other compounds (1.54\% total content).

Butanoic acid (No.1) detected in the non-fermented pork jerky wass not found in the pork jerky. Butanoic acid has strong, unpleasant smells of cream and cheese, and it has a creamy taste. The odor threshold of butanoic acid in a $12 \%$ solution of alcohol in water is $10000 \mathrm{ug} / \mathrm{L}$ (Guth, 1997). The non-fermented pork jerky contained a small amount of butanoic acid (2.912\%). After fermentation, butanoic acid disappeared, which improved the meat's flavor. DL-glutamic acid (No. 3) is sour and has an odor threshold of $50 \mathrm{ng} / \mathrm{L}$; D-glutamic acid is tasteless and primarily used as a flavor enhancer (Fan and $\mathrm{Xu}, 2014$ ).

1-Hexanol (No. 5), which has an odor threshold of
$2,500 \mu \mathrm{g} / \mathrm{kg}$, can be used in the food industry in baked foods, pudding, and meat products (Fan and $\mathrm{Xu}, 2014$ ). Phenylethyl Alcohol (No. 6), which has an odor threshold of $12-24 \mu \mathrm{g} / \mathrm{L}$ in the air and an odor threshold of $1,000 \mu \mathrm{g} / \mathrm{L}$ in water, can be used for preparation of roses, caramel, honey, and various liquor and tobacco flavors. It is also an indispensable substance in the scents of roses and other plants. Ethyl alcohol (No. 7), which has an odor threshold of $100,000 \mu \mathrm{g} / \mathrm{kg}$, is used to manufacture acetic acid, beverages, flavors, dyes, fuels, etc. (Fan and $\mathrm{Xu}, 2014$ ). 1-Octen-3-ol (No. 8), which has a smell of unprocessed mushrooms and is also known as Mushroom Alcohol, has an odor threshold of $0.01 \mathrm{mg} / \mathrm{kg}$; it is one of the key components of the overall flavor of Camembert cheese (Hou et al., 2014). 1-Pentanol (No. 9), which has an odor threshold of $4,000 \mu \mathrm{g} / \mathrm{kg}$, is used for organic synthesis and has a slight smell (Zhang et al., 2013). Nonanal (No. 10), which has an odor threshold of $1 \mu \mathrm{g} / \mathrm{kg}$, plays a significant role in pork flavor. Pentanal (No. 11), which has an odor threshold of $20 \mu \mathrm{g} / \mathrm{kg}$, is primarily used as a flavor, intermediate for organic synthesis, and rubber accelerator (Mo et al., 2007). 3-Methyl-Butanal (No. 12), which has an odor threshold of $1 \mu \mathrm{g} / \mathrm{kg}$, is used as a food material, flavor, reagent, etc. (Zhang et al., 2013) (Table II).

Table II.- Volatile compounds of fermented and non-fermented pork jerkies.

\begin{tabular}{|c|c|c|c|c|}
\hline \multirow[t]{2}{*}{ No. } & \multirow{2}{*}{ Volatile compounds } & \multirow{2}{*}{$\begin{array}{l}\text { Retention } \\
\text { time }\end{array}$} & \multicolumn{2}{|c|}{ Pork jerkies } \\
\hline & & & Non-fermented & Fermented \\
\hline \multicolumn{5}{|c|}{ Acids } \\
\hline 1 & Butanoic acid & 26.944 & $2.912 \%$ & \\
\hline 2 & 2-(14-Carboxytetradecyl)-2-ethyl-4, 4-dimethyl-1,3-oxazolidine-N-oxyl & 14.6329 & & $0.16 \%$ \\
\hline 3 & DL- Glutamic acid & 12.8385 & & $0.51 \%$ \\
\hline \multicolumn{5}{|c|}{ Alcohols } \\
\hline 4 & 1-Nonanol & 13.3762 & & $0.21 \%$ \\
\hline 5 & 1-Hexanol & 13.7025 & & $2.53 \%$ \\
\hline 6 & Phenylethyl Alcohol & 21.267 & & $0.15 \%$ \\
\hline 7 & Ethyl Alcohol & 6.3132 & & $5.38 \%$ \\
\hline 8 & 1-Octen-3-ol & 15.0136 & & $1.99 \%$ \\
\hline 9 & 1-Pentanol & 12.1799 & $1.14 \%$ & $1.90 \%$ \\
\hline \multicolumn{5}{|c|}{ Aldehydes } \\
\hline 10 & Nonanal & 14.349 & & $0.88 \%$ \\
\hline 11 & Pentanal & 7.0805 & & $7.93 \%$ \\
\hline 12 & 3-Methyl-Butanal & 10.9594 & & $2.02 \%$ \\
\hline 13 & Benzaldehyde & 16.367 & $0.78 \%$ & $0.93 \%$ \\
\hline 14 & Hexanal & 9.1287 & $63.58 \%$ & $60.18 \%$ \\
\hline \multicolumn{5}{|c|}{ Others } \\
\hline 15 & 2-pentyl- Furan & 11.5213 & & $1.37 \%$ \\
\hline 16 & 1-methyl-4- (1-methylethyl)- Benzene & 12.331 & & $0.17 \%$ \\
\hline
\end{tabular}


2-Pentyl- Furan (No. 15) is a primary flavoring substance with an odor threshold of $270 \mathrm{ng} / \mathrm{L}$ in the air and an odor threshold of $6 \mu \mathrm{g} / \mathrm{L}$ in water (Fan and $\mathrm{Xu}, 2014$ ). It is a primary flavoring substance in meat that smells of caramel and fruit. It is also found in many foods such as fruits, vegetables, meats, baked foods, coffee, cocoa, tea, and fish, and even spirits (Zhang et al., 2013) (Table II).

Analysis revealed that DL-Glutamic Acid (No.3), Phenylethyl Alcohol (No. 6), 1-Octen-3-ol (No. 8), Nonanal (No. 10), Pentanal (No. 11), 3-Methyl-Butanal (No. 12), and 2-Pentyl- Furan (No. 15) play important roles in pork jerky production (Table II).

\section{ACKNOWLEDGEMENTS}

This work was financially supported by Science and Technology Department of Sichuan Province (Item No. 2016RZ0063) and Sichuan University of Science and Engineering (Item No. 2012RC10).

\section{Statement of conflict of interest}

Authors declare that there is no conflict of interests regarding the publication of the manuscript.

\section{REFERENCES}

Aqib, A.I., Ijaz, M., Durrani, A.Z., Anjum, A.A. and Hussain, R., 2017. Prevalence and antibiogram of staphylococcus aureus, a camel mastitogen from Pakistan. Pakistan J. Zool., 49: 861-867. https:// doi: 10.17582/journal.pjz/2017.49.3.861.867

Chen, G.S. and Liu, M.Y., 2004. Analysis of nutritional characteristics of wild crossbred pig muscle. Swine Prod., 1: 24-27.

Drosinos, E.H., 2006. Phenotypic and technological diversity of lactic acid bacteria and staphylococci isolated from traditionally fermented sausages in southern Greece. Fd. Microbiol., 24: 1-11.

Gu, R.Y., Yao, M.J. and Fu, W.C., 2009. Production technology of jerky, dried meat in threads or sliced form, and dried meat floss. Chemical Industry Press, Beijing, China.

Guth, H., 1997. Quantitation and sensory studies of character impact odorants of different white wine varieties. J. Agric. Fd. Chem., 45: 3027-3032. https://doi.org/10.1021/jf970280a

Hammes, W.P. and Knauf, H.J., 2001. Starters in the processing of yeasts in traditional sausages of southern Italy. FEMS Yeast Res., 1: 161-167. https:// doi.org/10.1111/j.1567-1364.2001.tb00027.x

Hou, J.P., Liu, Z.M., Hang, F., Yu, H.N., Guo, B.H. and Li, Y.F., 2014. Lipolysis in cheese and flavour development. Fd. Ferment. Indust., 40: 154-159.

Konieczny, P., Stangierski, J. and Kijowski, J., 2007. Physical and chemical characteristics and acceptability of home style beef jerky. Meat Sci., 76: 253-257. https://doi.org/10.1016/j. meatsci.2006.11.006

Lee, J.Y., Kim, C.J. and Kunz, B., 2006. Identification of lactic acid bacteria isolated from kamahi and studies on their suitability for applications as starter culture in the production of fermented sausages. Meat Sci., 72: 437-445. https://doi.org/10.1016/j. meatsci.2005.08.013

Li, C.T. and Lv, J.L., 2005, Development trend of Lactobacillus and its fermented dairy products. China Brew., 8: 5-7.

Li, K.X., Jiang, C.H., Tang, M.X. and Feng, S.J., 2004. Application of moulds in fermented sausages. Meat Indust., 12: 33-36.

Mo, S.P., Lin, J.H., Bai, J.L. and Zheng, W.L., 2007. The flavour compounds of meat products and it's examination. China Condiment, 335: 25-30.

Fan, W.L. and Xu, Y., 2014. Flavor chemistry of alcoholic beverage. China Light Industry Press, Beijing, China, pp. 170.

Visessanguan, W., Benjakul, S., Riebroy, S., Yarchai, M. and Tapingkae, W., 2006. Changes in lipid composition and fatty acid profile of Nham, a Thai fermented pork sausage, during fermentation. Fd. Chem., 9: 580-588. https://doi.org/10.1016/j. foodchem.2004.11.051

Wang, M., 2013. The research advances of fermented sausages and its starter culture. Jiangsu Season. Fd., 3: 4-9.

Wu, G.F., Li, G.Q. and Ma, Y.Q., 2006. Industrial fermentation analysis. Chemical Industry Press, Beijing, China, pp. 43-46.

Xia, Y.B., 2008. Flavor chemistry for food. Chemical Industry Press, Beijing, China, pp. 150.

Zhang, S.H., 2005. Food analysis. China Light Industry Press, Beijing, China.

Zhang, X.Y., Xia, S.Q., Hua, J. and Jia, C.S., 2013. Flavor chemistry for food. China Light Industry Press, Beijing, China, pp. 172-175.

Zhou, G.S., 1996. Quantitative detection of true protein in feed. China Feed, 7: 33. 